\title{
Para um conceito materialista de tempo musical. A teoria dos tipos nos fragmentos de Adorno sobre Beethoven
}

\author{
Towards a Materialistic Concept of Musical Time. The Theory
}

of Types in the Fragments of Adorno on Beethoven

\author{
Eduardo Socha \\ Universidade Federal de São Carlos [uFscar]
}

\section{RESUMO}

Pretende-se expor os elementos principais da teoria dos tipos, que encontramos nos Beethoven-Fragmente, de Theodor W. Adorno. Por meio desse modelo de pensamento, Adorno esclarece os critérios orientadores de seu conceito de tempo musical, que se particulariza criticamente nos escritos musicais posteriores, como as monografias sobre Wagner, Mahler e Berg, os ensaios sobre Stravinsky e as conferências sobre o serialismo pós-Webern. A teoria dos tipos envolveria as diferentes modalidades de "relação da música com o tempo em geral". Além da exposiçâo teórica, articulada à interpretaçáo do tempo em Hegel, propóe-se a análise técnica de peças de Beethoven, sobretudo do $\mathrm{I}^{\mathrm{O}}$ movimento da $3^{a}$ Sinfonia, obra que fundamentaria in $m u$ sicis o conceito adorniano de tempo musical.

\section{PALAVRAS-CHAVE}

Adorno; Filosofia da música; Tempo musical; Beethoven; Hegel.

\begin{abstract}
This article analyses the fundamental elements of Adorno's theory of Beethoven's types, as developed in his Beethoven-Fragmente. This theory, as a thought-model, reveals the criteria which prompt Adorno's interpretations of musical temporality in his subsequent musical writings, such as the Essay on Wagner, his monographs on Mahler and Berg, his critical essays on Stravinsky, his conferences on post-Webern serialism. In fact, the theory of types would cover the different modalities of the "relationship of music and time in general". This article presents also a technical analysis of some of the Beethoven's works commented by Adorno, such as the $\mathrm{I}^{\text {st }}$ movement of Beethoven's $3^{\text {rd }}$ Symphony, a piece that would establish in musicis Adorno's model.
\end{abstract}

\section{KEY WORDS}

Adorno; Philosophy of Music; Musical Time; Beethoven; Hegel. 


\section{Os fragmentos sobre Beethoven}

Durante pelo menos vinte anos, Adorno trabalhou em um livro sobre Beethoven. As notas preparatórias, os registros de diário, os fragmentos e os textos avulsos para o livro foram coligidos e finalmente lançados em 1993 por Rolf Tiedemann (também editor das Obras reunidas) em um volume com o título originalmente proposto por Adorno: Beethoven - Philosophie der Musik. O alcance e a audácia do projeto já se manifestam na escolha do título. Por meio da análise imanente da obra de Beethoven, Adorno pretendia decifrar o teor de verdade não apenas da apropriaçáo especulativa da forma-sonata pelo compositor (tomada como equivalente formal ao "sistema conceitual" hegeliano), mas da própria tonalidade diatônica como fenômeno estético-social associado à ascensão da burguesia no plano político. Filosofia idealista e tonalidade, produçôes espirituais coetâneas da burguesia europeia, estabeleceriam uma estrita homologia que Adorno procurou sublinhar no trabalho inacabado sobre Beethoven: "assim como a tonalidade coincide, historicamente, com a era burguesa, ela é, em termos de significado, a linguagem musical da burguesia" (Adorno, 1993, \$I13); ao mesmo tempo, "o sistema idealista em Beethoven é a tonalidade [...]. E, assim como a música de Beethoven, a tonalidade é o todo" (ibid., \$35). Beethoven representaria o apogeu da reflexão dialética no plano da construção musical, e é nesse sentido que, para Adorno, "entender Beethoven significa entender a tonalidade" (ibid., \$II2).

O fato de o livro não ter sido concluído por Adorno - um escritor de produção notoriamente vasta - revela a dimensão desses Beethoven-Fragmente. De acordo com manuscritos e correspondências, as primeiras notas datam de 1937; em 1959, Adorno teria aparentemente desistido do livro, após a publicação do ensaio Verfremdetes Hauptwerk, Zur Missa Solemnis. ${ }^{I}$ Náo seria estranho supor que o livro nunca poderia ter sido escrito por Adorno, tendo em vista o caráter totalizante do empreendimento, que se evidencia no título ("Filosofia da música"), e ao qual os fragmentos mais elaborados, de teor assertivo, dão testemunho. Para Tiedemann, Adorno teria reconhecido de maneira cifrada a inviabilidade do livro já no final dos anos 1940, ao declarar em Filosofia da nova música (FNM) que uma "filosofia da música hoje só é possível como filosofia da nova música" (Adorno, GS I2, 19). No entanto, é preciso ter em conta dois fatores que atenuam o valor de face dessa declaração: em primeiro lugar, as referências a Beethoven em FNM são bastante frequentes e não podem ser consideradas episódicas; depois de Schoenberg e Stravinsky, Beethoven é o nome mais citado no livro. ${ }^{2}$ Em segundo lugar, no ensaio

I Apesar disso, pouco antes de sua morte, em janeiro de 1969, Adorno voltou a incluir Beethoven - Philosophie der Musik na lista dos livros que ainda esperava concluir, conforme as notas de sua reunião com o editor Siegfried Unseld, da Suhrkamp. Cf. Tiedemann, Vorrede des Herausgebers, in Adorno, 1993. Adorno publicou somente dois textos específicos sobre Beethoven: Estilo tardio (1937) e Verfremdetes Hauptwerk (1959), ambos reunidos em Moments Musicaux (GS I7). Essa minguada bibliografia pode nos iludir quanto à centralidade de Beethoven para a filosofia adorniana.

2 "A presença mais marcante na Philosophie der neuen Musik, além de Schoenberg e Stravinsky, é a de Beethoven. Talvez ele seja, depois dos dois principais compositores, a figura central da Philosophie der neuen Musik". (Waizbort, I992, p. 184) 
Sobre a relação contemporânea entre filosofia e música (1953), portanto após a publicação de FNM, Adorno utiliza a expressão "filosofia da música" para se referir ao modelo de pensamento que o conjunto da obra de Beethoven ofereceria. Ao tratar da relação dialética entre tempo empírico/histórico e formalização intra-estética do tempo, Adorno defende que uma "filosofia da música plenamente elaborada encontraria seu modelo na obra de Beethoven" (Adorno, GS I8, I60).

Há boas razôes para crer que a passagem não é meramente casual. Se os fragmentos sobre Beethoven confirmam a busca por uma "filosofia da música" mesmo nos anos I950 e 60, a declaração de FNM, redigida no final dos anos 40 e citada por Tiedemann, torna-se no mínimo irresoluta. Poderíamos nos perguntar se o livro, deixado em estágio de anotaçóes avulsas, não se coadunaria afinal com o caráter fragmentário da própria filosofia adorniana, expressando seu teor de verdade a contrapelo, em um curioso efeito de mis en abyme. A hipótese, à primeira vista extravagante e passível de pronta contestação, estaria amparada pelas próprias observaçôes que Adorno fez a respeito da ópera inacabada Moses und Aron, o "fragmento sacro" de Schoenberg: uma obra que, como musica ficta superada, como metáfora da tensão entre construçáo e expressão no percurso da prática compositiva de Schoenberg, só poderia existir como fragmento. ${ }^{3}$

Neste artigo, pretendemos expor os elementos principais de sua teoria dos tipos, que encontramos nos Beethoven-Fragmente. Trata-se de uma teoria materialista que explicita os critérios orientadores da reflexão de Adorno sobre o conceito de tempo musical, conceito que se particulariza criticamente em textos como o Ensaio sobre Wagner, as monografias sobre Mahler e Berg, os dois ensaios sobre Stravinsky, e nos ensaios sobre o serialismo pós-Webern dos anos 1950. A tipologia envolveria, a princípio, as modalidades de toda "relação da música com o tempo em geral".

\section{Teoria dos tipos}

A teoria dos tipos de Beethoven está descrita no fragmento \$219, e suas implicaçôes são desenvolvidas em fragmentos posteriores do livro. Fundamentalmente, a teoria consiste em três modalidades da relação da música com o tempo: modalidade de tipo intensivo, de tipo extensivo, e a modalidade do "estilo tardio" (esta última a crítica imanente das duas primeiras). Dois conjuntos de obras servem de base à classificação adorniana:

I) os primeiros movimentos das sinfonias $3^{\mathrm{a}}-$ Eroica, $5^{\mathrm{a}}$ e $7^{\mathrm{a}}$, e da sonata Appassionata seriam casos paradigmáticos do tipo intensivo;

2) os primeiros movimentos do Quarteto op. 59, I, da Sonata para violino op. 96, do Trio op. 97, da 6a sinfonia Pastoral seriam exemplares do tipo extensivo.

Nesse decisivo fragmento $\$ 219$, redigido em 1940, Adorno procura estabelecer os termos concretos da teoria que, como dissemos, é retomada em passagens ulteriores de seus escritos, com terminologia eventualmente alterada (como, por exemplo, a antinomia

3 Adorno, GS I6, 454: "[...] Moses und Aron é um fragmento, e não seria descabido dizer que a ópera permaneceu incompleta justamente porque não poderia ser concluída”. 
entre dramático e épico nas monografias sobre Wagner e Mahler). Pela relevância para nosso propósito, transcrevemos os trechos principais do fragmento:

Uma teoria dos tipos de Beethoven e de seus caracteres deve ser providenciada. Os tipos são independentes de tipos formais. Existe um tipo intensivo e um tipo extensivo, cada um dos quais - na relação da música com o tempo - algo fundamentalmente diferente é ambicionado. O tipo intensivo visa a uma contração do tempo [Kontraktion der Zeit]. É o verdadeiro tipo sinfônico, que tentei definir em meu [ensaio] Zweite Nachtmusik. É o verdadeiro tipo clássico. O tipo extensivo pertence especialmente ao período médio/tardio [...]. Representativos deste tipo são o $\mathrm{I}^{\circ}$ movimento do $o p$. 59, I (o op. 59, 2 é exemplar do tipo intensivo, próximo do $\mathrm{I}^{\mathrm{o}}$ movimento da 'Appassionata'); $\mathrm{I}^{\mathrm{o}}$ movimento Trio op.97; $\mathrm{I}^{\mathrm{o}}$ movimento da Sonata para Violino op. 96. Esse tipo é muito difícil de determinar [...]. Poderíamos falar talvez de uma relação geométrica — em vez de dinâmica — com o tempo. [...]. Raramente há alguma mediação, aspectos do estilo tardio aparecem aqui [...]. O princípio de organização da forma extensiva ainda é obscuro para mim. A forma extensiva contém certo momento de renúncia, abandono do equilíbrio dos opostos [...] contribui à contingência, no sentido de que, na constituição da forma, um maior peso é dado ao tempo abstrato do que à construçấo do tempo. Mas esse momento do tempo torna-se, como no romance, um tema e a coisa principal [...]. A abdicação diante do tempo [Abdikation vor der Zeit] e a configuração [Gestaltung] dessa abdicação fazem a substância do tipo extensivo. Predileção por grandes extensóes temporais (op. 59, I e Trio op. 97) é importante aqui. A Nona (Sinfonia), nesse sentido, é a tentativa de articular os tipos intensivo e extensivo. O estilo tardio contém ambos; certamente é o resultado do processo de desintegração [Zerfallprozess] representado pelo tipo extensivo mas, mantendo o princípio intensivo, reorganiza os fragmentos quebrados por ele [...]. A falta de suavidade é característica do tipo extensivo (Adorno, 1993, \$219, grifos do original).

Esse texto estabelece uma demarcação nítida quanto aos modos de configuração intra-estética do tempo. O tipo intensivo ou sinfônico corresponde à tentativa de realizar a contração da passagem temporal [Kontraktion der Zeit] em um instante carregado de sentido pelas suas relaçóes internas ou, dito de outro modo, de produzir uma unidade dialética entre totalidade e particularidade, cuja objetivação confronta o tempo empírico, denominado acima "tempo abstrato". Devemos ter em mente que o tempo empírico constitui, para Adorno, "a mais profunda expressão das relações de dominação no interior do campo da consciência” (GS 3, 313). Já o tipo extensivo cobre o conjunto complementar de modelos, de complexa organização ("difícil de determinar"; "ainda é obscuro para mim"), que se materializa em certa renúncia ao confronto com a dimensáo empírica do tempo para simplesmente "preenchê-lo": ao dar "maior peso ao tempo abstrato do que à construção do tempo, o tipo extensivo consiste na negação determinada do tipo intensivo. $\mathrm{O}$ estilo tardio confirma, por fim, a superação dialética dos dois tipos, fornecendo um modelo singular de crítica à ideologia em sua lógica de desintegração (extensivo) que, não obstante, preserva o princípio de construção (intensivo). 
Notemos que os tipos não se referem a realidades antagônicas, não mediadas, como se Adorno estivesse apresentando dois conceitos de tempo conflitantes entre si. De acordo com Klein, a teoria dos tipos simplesmente confirma a tese de que "o conceito de tempo [der Zeitbegriff] de Adorno, encarnado pelo tipo intensivo, já é, em si, cindido"; ou seja, confirma a tese de que a efetivação composicional desse conceito tornou-se historicamente impossível em razão dessa cisão interna (Klein, 2oII, p. 67). Vale ressaltar também que os tipos deduzidos a partir de Beethoven não correspondem a gêneros de uma poética normativa. Não se trata de uma preceptiva, de regras que a criação artística deveria atender para a ampliaçáo de efeitos, tampouco de categorias de uma estética idealista, visando o conhecimento sistemático dos objetos independentemente de seu momento histórico de produção e recepção. Na filosofia de Adorno, os tipos funcionam como operadores descritivos das modalidades de configuração temporal da totalidade nas obras, analisadas em contexto. Tal especificidade fica evidente, por exemplo, na flutuação semântica que o "tipo épico-extensivo" adquire nos escritos musicais (diferente em Beethoven, na monografia sobre Mahler e nas conferências sobre o serialismo dos anos I950). Dito de outro modo, não há lugar para conceitos universais de dramático-intensivo ou de épico-extensivo desvinculados da singularidade formal das obras. Por outro lado, embora a teoria tenha permanecido em estágio de esboço, veremos que os tipos revelam os critérios orientadores para a crítica adorniana das configuraçóes do tempo musical, de Bach a Boulez. Por fim, é importante sublinhar também que o critério de distinção dos tipos não se refere à extensão cronométrica dos movimentos, mas à configuração qualitativa e intra-estética de sua totalidade.

\subsection{Tipo intensivo ou dramático}

O tipo intensivo origina-se, como se viu, de uma modalidade particular de apropriação da sonata clássica no Beethoven do período médio e alicerça a noção de tempo sinfônico ou dramático — os termos "intensivo", "sinfônico", "dramático" são usados como sinônimos por Adorno. Em Über die musikalische Verwendung des Radios (1963), publicado mais de duas décadas depois da escrita do fragmento \$219, citado acima, Adorno define o tipo sinfônico não como a simples ideia de uma "sonata para orquestra", mas como o resultado de uma "urgência compacta, concisa, palpável: a técnica do trabalho motívico-temático" (GS I5, 376). Trata-se, para ele, de uma forma de resolução do ideal utópico da música em sua "luta contra o mito", contra o "tempo vazio" [leere Zeit], uma forma cuja suspensão da empiria constitui a base, como veremos, do paradigma da Entwicklung musical, ou, simplesmente, a base do tempo musical na filosofia adorniana.

As obras do tipo intensivo fundamentam-se pelo denso trabalho orientado à construção do conflito temático, à sucessividade e à irreversibilidade processual dos eventos sonoros. A origem dessa modalidade específica de submissão musical do tempo ocorreria na transição da "música pré-clássica à sinfonia", de acordo com a periodização esboçada no ensaio Zweite Nachtmusik (1937) (conforme a citação acima, "é o verdadeiro tipo sinfônico, que tentei definir em meu [ensaio] Zweite Nachtmusik”). Este período, segundo 
Adorno, teria sido marcado pela conquista de um dinamismo sem precedentes do pensamento motívico-temático, cuja virtude foi a de liberar a lógica musical da dependência da estaticidade e da "repetição" imposta pela sua função social de divertimento. Desse modo, no ensaio Zweite Nachtmusik, Adorno já utilizava o termo "repetição" [Wiederholung] como sinônimo da rejeição à "construção do tempo musical": "repetição" seria a mera conformação não dialética dos eventos musicais ao tempo empírico, conformação mítica com a passagem vazia do tempo. Adorno afirma que somente a partir do classicismo vienense, a partir de Haydn e Mozart, se consolidaria a tentativa de superar a lógica da repetição mítica por meio da valorização do elemento particular, basicamente a figura da "antifonia motívica". Tal valorização seria capaz de, no caso de Beethoven, tensionar de modo imanente a totalidade formal da obra, até entáo imposta "de cima para baixo", ou seja, o esquema determinando a posição do particular. Esse modo inovador de uma forma que buscaria o equilíbrio entre totalidade e elemento particular, modo que fundamenta o tipo intensivo, seria descrito anos depois, e não por acaso, através da categoria de "intensidade" [Intensität] em Teoria Estética. ${ }^{4}$

Notemos que a "forma do sinfônico", forma dessa "grandeza intensiva", inaugura na história da música a preocupação com a totalidade dinâmica dos detalhes, o trabalho motívico-temático. A relação entre o particular e o universal — totalidade da forma se converte em relação dialética entre momento expressivo, composto pela sublimação gestual e mimética, e momento construtivo, que estabelece a síntese lógica do fluxo musical. Em Zweite Nachtmusik, mencionado no fragmento \$219, Adorno delimita a especificidade da "forma do sinfônico" (der 'Symphonik') como praticamente sinônimo de tipo intensivo. No final desse ensaio, Adorno propõe uma incipiente periodização da história da música ocidental. Para o autor, a música polifônica pré-clássica de I60o a I750, por ainda estar ligada à função social de Divertimento ou à eventual função disciplinar, não chegava a "confrontar" (bewältigen) dialeticamente a passagem empírica do tempo, restringindo-se apenas a "preenchê-lo" (erfüllen). Isso tornava impraticável a composição de obras de larga extensão temporal. A expressão histórico-musical da subjetividade, ainda enfraquecida no período anterior à emancipação política da burguesia, apenas preenchia o tempo empírico através de convençôes harmônicas e padrôes melódicos repetitivos; a exteriorização da subjetividade composicional, que Adorno vincula ao trabalho motívico-temático, leva-o a caracterizar todo o período pré-clássico como período de "tédio estético" (ästhetischen Langeweile) — "exceçôes feitas a Monteverdi, Scarlatti, Bach e Pergolesi" (Adorno, Gs I8, 5I). Trata-se de um período que prepararia a Aufklärung musical.

4 Adorno, Gs 7, 279: "O entrelaçamento do particular e do múltiplo nas obras de arte pode ser apreendido na questão pela sua intensidade. A intensidade é a mimesis realizada pela unidade, cedida pela multiplicidade à totalidade, embora esta náo esteja imediatamente presente a ponto de ser possível percebê-la como grandeza intensiva; a força nela acumulada é por assim dizer restituída por ela ao detalhe [...] a grande unidade entre composição e construção parece [scheinen] querer existir apenas em tal intensidade". 


\section{A "antifonia motívica" e o conceito de Entwicklung}

Em sua descrição da "antifonia motívica"s, Adorno define então o motivo como um Zeitdifferential, a unidade básica diferencial para a criação de relaçóes temporais (GS I8, 5I). É a partir da qualidade do trabalho motívico-temático que se estabelece ou a contração dialética, no caso do tipo intensivo, ou o mero "preenchimento", no tipo extensivo, da dimensão intra-estética do tempo. Podemos dizer que a ênfase na qualidade do tratamento motívico, como aquilo capaz de estruturar o tempo musical a partir de uma unidade básica diferencial, procede claramente de Schoenberg. Segundo Dahlhaus, a ideia de "diastema motívico" - a relação intervalar básica no campo das alturas, a "antifonia motívica" - constituía para as análises de Schoenberg a verdadeira substância da arte musical (Dahlhaus, 1989, pp. I3O-I3I). Embora os demais elementos também contribuíssem para formar o conteúdo, eles seriam considerados subsidiários, mera superfície e modo de apresentação da "ideia inspiradora" [Einfall], e não constitutivos da própria ideia. Ou seja, enquanto a formação de regularidades métricas e de coerência harmônica apenas reforçaria uma lógica musical pré-definida motivicamente, a essência da música para Schoenberg estaria nos complexos intervalares ${ }^{6}$. Adorno, seguindo estritamente a concepção de Schoenberg, também parece atribuir à relação diastêmica intervalar do pensamento motívico o núcleo do tipo sinfônico.

No \$163 dos Beethoven-Fragmente, encontramos uma definição do conceito de Entwicklung, conceito que, para Adorno, mobiliza "uma das questóes mais centrais da estética musical”. É digno de nota que este fragmento tenha sido redigido em 1956, no mesmo ano em que Boulez e Stockhausen publicavam suas primeiras teorizaçóes sobre a natureza do tempo musical. Notemos que a característica central do conceito de "desenvolvimento", Entwicklung, seria a "irreversibilidade do tempo":

É necessário esclarecer o conceito de desenvolvimento musical (Entwicklung) no texto. Não é idêntico àquele da variação, mas bem próximo. Um momento central é a irreversibilidade do tempo. Desenvolvimento é uma variação na qual um elemento ulterior pressupóe algo anterior como anterior, e não o contrário. De modo geral, a lógica musical não é simplesmente identidade na não-identidade, mas uma sequência significativa de momentos; isto é, o que vem antes e o que vem depois devem constituir sentido a partir de si ou ser o resultado

5 Basicamente, a antifonia consiste na interação entre dois coros no estilo pergunta e resposta, comum nos serviços litúrgicos medievais (ex.: o "antifonário" eclesiástico). No entanto, Adorno compreende a "antifonia motívica" em sentido etimológico, apenas como arte da composição de "vozes contrastantes", simplesmente a elaboração motívica; em outro contexto, Adorno também utiliza a expressão "antifonia" para descrever a relação entre notas (alturas), a exemplo da oposição entre "nota individual" e "relação entre notas".

6 "Em uma análise da primeira de suas Cançóes para orquestra, op. 22, Schoenberg define o semitom e a terça menor como sendo 'sempre a mesma substância', independentemente do ritmo e da articulação” (Dahlhaus, I989, p. I3I). O musicólogo considera que tal concepçáo diastêmica do motivo, fundamentada no campo das alturas, revela-se problemática ao relegar tanto a constituição rítmica quanto a própria articulação, que todavia seriam indispensáveis para a essência perceptiva do motivo. 
dele. Evidentemente, as possibilidades para isso são muitas, por exemplo: algo intenso que ascende a partir de algo fraco, algo complexo a partir do simples; essa direção (simples para complexo), porém, de modo algum define o conceito. Pode também resultar no elemento simples: o tema; pode simplificar o complexo, dissolver o fechado, e assim por diante. Esses tipos poderiam ser enumerados; mas apenas a composição concreta decide qual será a lógica do que vem antes e o que vem depois. Ou existiriam leis gerais? Uma das questôes centrais da estética musical (Adorno, 1993, \$163).

Se o trecho parece elíptico demais para o propósito de "esclarecer o conceito", a descrição confirma claramente o compromisso teórico de Adorno com um ideal de continuidade e construção progressiva de sentido na arte musical denominado Entwicklung. É interessante observar que o conceito de Entwicklung — "próximo", mas não idêntico ao de "variação" — conduz esse ideal de irreversibilidade para além do campo harmônico-melódico, ou seja, para além da simples "antifonia motívica" no campo das alturas. Embora tenha sua origem no conceito de variação (em alusão à "variação em desenvolvimento"), Entwicklung aqui não se limita à dimensão harmônica ou melódica. Em Critérios da NM, de 1957, Adorno chega a elaborar um inventário de "categorias de desenvolvimento" 7 - e isso parece-nos decisivo se quisermos afastar a hipótese do suposto "ponto cego" adorniano quanto ao desenvolvimento de novos modelos rítmicos e novas texturas timbrísticas na vanguarda dos anos 1950, anátema da suposta afinidade incondicional adorniana com o pensamento temático tradicional. Tal hipótese deve ser descartada, mesmo quando Adorno se propóe a preservar o conceito de Entwicklung para avaliar a música atemática. A ligação entre o "agora" e o "depois", a reação de um evento sonoro à ação de um anterior, ocorreria de direito mesmo na música atemática: "Mesmo na música atemática, as relaçóes entre o agora e o depois não devem ser arbitrárias, devem estar legitimadas no curso do tempo, não simplesmente em virtude da identidade matemática estática de suas partes constituintes" (Adorno, GS I6, 223).

Por outro lado, é importante ressaltar que é o trabalho motívico-temático, conduzido ao extremo durante o período médio de Beethoven, que engendra o conceito adorniano de Entwicklung. Ainda que possa ser aplicado a outras dimensôes da organização sonora, sua origem localiza-se de fato no "diastema motívico", na relação intervalar simples: o conceito não se limita à construção motívico-temática, mas se origina dela. A relevância da formação identitária do motivo, como unidade essencial para a construção de relaçôes temporais, torna-se explícita nos fragmentos sobre Beethoven quando se oferece uma descrição da forma da fantasia. Por exemplo, na fantasia mozartiana, a irrupção contínua de um material que se limita à apresentação de novos temas, sem passar por transformaçôes ou variaçôes, acaba transformando a obra paradoxalmente em estática: o tempo musical não existe. Justamente por abdicar da posição de um núcleo idêntico

7 A elaboração dessa tipologia está em Adorno, Critérios da nova música, GS 16, 223: "Immerhin wäre eine Typologie von Entwicklungskategorien heute bereits absehbar [...]” (grifo meu). 
e reconhecível para posteriores variaçóes, o não-idêntico, a fantasia mozartiana, para Adorno, simplesmente não se desenvolve:

Essa forma da fantasia (de Mozart) é essencialmente estática. Como o novo sucede ininterruptamente (Neues aufeinander folgt), nenhum progresso é realmente feito. Não há núcleo idêntico a ser desenvolvido. Sem tal identidade, porém, não há não-identidade e, portanto, não há tempo musical. [...] Do mesmo modo, a música consistentemente a-temática seria, em princípio, a-temporal, e a qualidade estática da música dodecafônica apenas torna manifesto o que é inerente no nominalismo musical absoluto: que a novidade incessante revoga a progressão, a experiência, o novo" (Adorno, 1993, \$165, grifos meus).

Cabe destacar dois aspectos do fragmento acima: em primeiro lugar, a rejeição à posição do elemento idêntico, núcleo motívico reconhecível a partir do qual se desenvolve o trabalho subjetivo do não-idêntico, implica abdicar da construção do tempo musical; em segundo lugar, construção do tempo musical e consistência da obra não necessariamente andam juntos - uma obra pode ser totalmente consistente, mesmo quando não segue o ideal da Entwicklung, mesmo quando não "constrói” o tempo. A mera exposição ininterrupta de materiais temáticos, que caracteriza a fantasia mozartiana, impede a posição de um idêntico. Para Adorno, a contradição do tipo sinfônico reside no fato de que a exteriorização progressiva e instável da não-identidade depende da posição estável de um elemento idêntico a ser transformado. É assim que, como Adorno sustenta em Zweite Nachtmusik, a repetição na antifonia motívica torna-se essencial:

O deslocamento [Versetzung] da interação motívica antifônica consegue fazer com que a repetição de motivos não recaia no tédio [Langeweile] [...]. Na antifonia, o motivo aparece como algo sempre novo e obedece, em suas transformaçôes, à exigência da passagem do tempo historicamente determinado, passagem que sua identidade virtualmente suspende [aufhebt] (Adorno, GS I8, 52).

Lembremos que, segundo a periodizaçáo adorniana, a lógica musical inicia um processo de confrontaçáo com o tempo abstrato e de afastamento do tédio somente a partir da sinfonia no classicismo, ainda que antecipada pela expressividade de Bach. Assim, o problema do "tempo musical" nasce no período de confrontação dialética com o "tempo empírico" [empirische Zeit]: até então o tempo musical não constituía sequer um "problema" a ser resolvido. Com o classicismo, surge um modelo dinâmico, no qual "o próprio Ser vira processo e seu resultado". ${ }^{8}$ Dito de outro modo, o problema do tempo musical nasce quando o conceito de uma totalidade dinâmica e processual reverbera a alteração das estruturas políticas europeias e a correlata expansão ideológica da racionalidade instrumental no plano social.

8 Ver em Sobre a relação contemporânea entre filosofia e música, a mesma ideia de Zweite Nachtmusik. Cf. GS I8, I59. 
Beethoven representaria o triunfo da cultura da alta burguesia antes do colapso da unidade mediada entre sujeito e objeto, entre individualidade e coletividade. Essa conquista da plena autonomia, da conciliação entre forma e conteúdo na $A u-$ fklärung, corresponderia à interiorização da antiga disposição heterônoma da música, até então ligada à função disciplinar, eclesiástica ou de entretenimento. Ou seja, a autonomia que permitiu a confrontação com o tempo empírico nada mais seria do que a introjeção dialética da antiga dimensão de divertimento, da antiga função mediante a auto-posição da lei formal (Adorno, 1993, \$IO7). No classicismo de Haydn e Mozart, haveria um equilíbrio formal entre "ser" e "devir": equilíbrio entre Sein, a apresentação clara dos temas e da "ideia" [Einfall], da identidade temática e, por outro lado, Werden, o trabalho de desenvolvimento, devir do tema, o não-idêntico.

A teleologia da forma no primeiro classicismo, refratária à concepção circular e "tediosa" de tempo, acentuava o caráter processual de transformaçôes a partir de unidades motívicas estáveis. No entanto, o trabalho autônomo iniciado no classicismo só alcançaria seu apogeu com Beethoven, a ponto de apenas em poucas obras do período médio-tardio do compositor esse ideal utópico do tipo intensivo teria sido efetivamente concretizado. Em Beethoven, a reflexão musical atingiria a dissolução da própria arquitetura da sonata, de modo que "introdução, exposição temática, desenvolvimento temático e transição, início da seção de desenvolvimento, entrada da reexposição, não são mais claramente reconhecíveis" (Klein, 20II, p. 67). Se, em Haydn e Mozart, a "ideia" [Einfall] ainda estaria no Sein dos temas, com Beethoven, assistimos à sua torção dialética: a reflexão prioriza o Werden temático, o devir passa a constituir o próprio Einfall da composição. Com Beethoven, o devir temático leva à reconstrução subjetiva da forma de "baixo para cima", da particularidade como mediação da totalidade.

\section{0 elemento estranho: 0 40 tema da "Eroica"}

Náo seria o caso de enumerarmos os elementos técnicos que Adorno identifica em Beethoven para sua caracterização do tipo intensivo. Adorno interpreta a centralidade deste $4^{\circ}$ tema não tanto pela tensão que provoca no esquema específico da Eroica, mas a interpreta dialeticamente como exigência pura da essência desenvolvimentista da sonata, da sua necessidade interna de emergência do novo, do Werden:

O 'novo' tema do desenvolvimento talvez deva ser entendido como requerido precisamente pelas exigências puras e intrínsecas da forma elevada ao mais alto grau; estas solicitam o elemento diferente, a nova qualidade, como seu resultado. A forma imanente como aquela que produz a transcendência da forma [...]. O novo tema é o tema lírico [Gesangsthema] que foi omitido. Como posição [Setzung] foi suprimido - como resultado, é requerido - e é então recuperado, de acordo com o esquema que antes havia sido suspenso. Assim o tema, ele também,

9 Cf. Paddison, 1993, p. 235. Vale lembrar que tanto nos fragmentos sobre Beethoven quanto em FNM, Adorno atribuía à sonata clássica o equilíbrio entre rigor e liberdade, a unidade entre tempo espacial-matemático objetivo e tempo da experiência subjetiva (GS I2, I80). 
é absorvido pela forma imanente; ou seja, dentro da coda do movimento, ele tem agora sua própria reexposição [seine eigene Reprise] [...] (Adorno, 1993, \$232, grifos do original).

Chama a atenção na interpretação de Adorno o fato de que a dissolução da forma operada pela introdução do $4^{\circ}$ tema na seção de desenvolvimento é ela mesma legitimada pelo ideal de desenvolvimento inscrito na forma clássica da sonata "em seu mais alto grau”, ou seja, em sua ideia de expansão do trabalho motívico-temático. Isso seria confirmado com a "reexposição" do $4^{\circ}$ tema justamente na seção seguinte, na coda: essa "reexposição própria" [seine eigene Reprise] na coda eliminaria qualquer dúvida sobre a mera casualidade do novo tema. Beethoven promove, desse modo, o deslocamento de toda a estrutura mediante as novas posiçóes do $4^{\circ}$ tema: em vez de ser apresentado na primeira seção, na exposição, ele aparece deslocado na seçáo seguinte, no desenvolvimento; em vez de ser reapresentado na terceira seção, na reexposição, o tema reaparece deslocado na seção seguinte, na coda alargada. Haveria aqui a absorção imanente da forma pela forma (imanência esta que produziria a "transcendência" da forma). Na mobilidade interna mesma de seu plano arquitetônico, em seu "ir para frente", a forma em Beethoven conforma-se com o ideal de irreversibilidade do qual se originou a sonata clássica. Esse deslocamento promovido por Beethoven, que atendia às exigências da própria sonata "em seu mais alto grau", só pôde se efetivar, todavia, mediante um ato resoluto de ruptura com o esquema clássico.

Em outro contexto, na monografia sobre Mahler, Adorno apontava para a resistência da crítica especializada de assimilar o novo tema de Beethoven na Eroica como efetivamente novo, na medida em que "ofende o princípio econômico de reduzir todos os eventos a um mínimo de postulados" que caracterizaria o esquema clássico, ou seja, na medida em que "destrói a ficção de que a música é puro tecido de deduçôes". Por isso, continua Adorno, "muitos analistas repetidamente tentaram derivar esse novo tema do material da exposição" (GS I3, 220), reforçando a dificuldade de compreendê-lo como a emergência do imprevisto no ideal de irreversibilidade do esquema. Para Adorno, contudo, a introdução do $4^{\circ}$ tema efetivamente perturba a simetria formal.

\section{Hegel, dissolução do esquema}

Com o tipo intensivo - no qual o $\mathrm{I}^{\mathrm{o}}$ movimento da Eroica, "realmente a peça beethoveniana, seria a mais pura encarnação do princípio" (Adorno, I993, \$159) — questiona-se o esquema tripartite da sonata. Posição dos temas (exposição), antagonismo entre os temas (desenvolvimento) e resolução de conflito (reexposição) são reconfigurados em uma totalidade dinâmica, não mais abstrata como no classicismo. Na nova relaçáo entre totalidade e multiplicidade dos detalhes, a mediaçáo sobre o tema ou a figura motívica se sobrepóe à abstração formal, ou melhor, impóe-se ela mesma como forma. A categoria de totalidade dinâmica encaminharia, assim, o modelo utópico adorniano de dialética das partes em relação ao todo, por meio da "síntese não violenta", capaz de liberar a força do particular. Assim, se Adorno teve de fato uma visáo da obra de arte reconciliada como 
prefiguração de um todo social racional e não-dominador, "o objeto dessa visão positiva foi a música do período médio de Beethoven” (Jay, I995, p. I29).

Vimos que, nessa totalidade dinâmica, as relaçôes internas não se estabelecem mais entre seus momentos individuais, reguladas externamente pela forma (como no esquema clássico), mas, assim como na filosofia hegeliana, a totalidade resulta ela mesma da mediação concreta, processual e imanente ao momento individual. ${ }^{10}$ Nesse sentido, percebemos a estreita proximidade entre o tipo fundamentado no ideal de Entwicklung e o conceito especulativo de tempo em Hegel. A totalidade dinâmica aqui corresponderia ao próprio conceito hegeliano de tempo (e não à sua representação), na medida em que Hegel, como observa Paulo Arantes (2000, p. I09), faz do tempo "não o lugar em que se desenrola a mudança, mas a própria mudança pura". Em outras palavras, a síntese sucessiva, outro nome para a totalidade dinâmica, é o momento constitutivo da pura negatividade, a forma do negativo em si mesmo, sua inquietude (ibid., p. I3I).

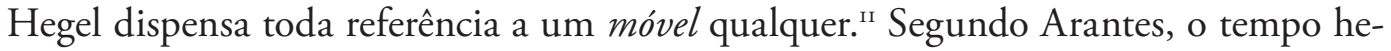
geliano não é a afecção do movimento, tampouco o receptáculo vazio a ser preenchido pela justaposição de eventos pontuais de indiferença recíproca. O Agora hegeliano não é substancial, mas é a consciência de sua própria negatividade, interiorização do devir. Ao se exteriorizar como trabalho do espírito, a forma da temporalidade do conceito especulativo se distingue da forma da duração [Dauer] inscrita na natureza ${ }^{\mathrm{I} 2}$; a primeira forma supera [aufhebt] a segunda, do mesmo modo que, no caso de Adorno, o tempo estético supera o tempo empírico. Notemos que, para Hegel, a duração natural não "progride", consiste na cíclica "repetição do mesmo" (ibid., p. 220). Já a negatividade produtiva do tempo liga-se à negatividade viva do conceito, é o "ser-aí imediato do Conceito" (ibid., p. 173). ${ }^{13}$ Sendo a "trama de sua prosa", a história emerge não da duração, mas do conceito; ou seja, o tempo hegeliano é sempre histórico, processo de des-naturação. $\mathrm{Na}$ medida em que se manifesta no trabalho do conceito, na atividade do espírito, a Entwicklung constituiria a força da "autoprodução" (trabalho de "des-envolver") do tempo. Lembremos que a Entwicklung musical para Adorno se caracteriza pelo fato de que "o que vem antes e o que vem depois devem constituir sentido a partir de si ou ser o resultado dele". Também para o conceito hegeliano de Entwicklung, a autoprodução de sentido implica tanto afastamento quanto adequação, conservando a relação antes-depois. Conforme Paulo Arantes,

IO Ideia exposta em diversos fragmentos. Cf. Adorno, I993, \$\$29; 44; 57.

II Arantes, 2000, p. I40. Paulo Arantes contrapóe-se à sugestão de Heidegger, para quem "o conceito hegeliano foi diretamente haurido na Física de Aristóteles" (ibid.).

I2 Ibid., p. 2II. Tempo e duração distinguem-se pois "a natureza não compreende a si mesma, e é por isso que a negatividade de suas formaçóes não existe para ela [...] História e não-história opóem-se e imbricam-se como tempo e duração" (ibid., p. 215). Nesse contexto, parece-nos razoável ver na duração natural a mesma essência correspondente ao tempo mítico/empírico na filosofia de Adorno.

I3 Ver ainda o $\$ 46$ da Fenomenologia do espirito: “[...] mas o tempo é o próprio conceito aí-essente. O princípio da grandeza - a diferença carente-de-conceito - , e o princípio da igualdade — a unidade abstrata sem-vida — não são capazes de apreender o tempo, essa pura inquietude da vida e diferenciação absoluta" (Hegel, 2002, p. 52). 
O desenvolvimento é esse movimento concreto da 'autoprodução própria do em-si em vista do ser-para-si'. Só se pode falar de Entwicklung graças a esse descompasso entre o em-si e o para-si, que na realidade não chega a ser um descompasso, já que de um ao outro há concomitantemente afastamento e adequação (Arantes, 2000, pp. 28I-282).

No tipo intensivo, os eventos musicais devem estar legitimados no curso do tempo, o que implica afirmar o movimento do em-si ao ser-para-si mediante sua processualidade: o tempo "deve ser articulado". A analogia torna-se ainda mais consistente se lembrarmos que Adorno propóe, nos fragmentos sobre Beethoven, o paralelismo entre trabalho do conceito [begriffliche Arbeit] em Hegel e trabalho temático [thematische Arbeit] em Beethoven ${ }^{\mathrm{I}}$, portadores da mesma experiência histórica de pensamento. Em Skoteinos, ensaio dos Três estudos sobre Hegel, Adorno apresenta uma analogia entre o trabalho conceitual na dialética e a progressividade da Entwicklung musical:

Uma música como a de Beethoven, na qual o ideal da reexposição — isto é, da rememoraçáo que produz o retorno de complexos anteriormente expostos - deve ser o resultado do desenvolvimento [Durchführung], como a dialética quer ser, oferece um análogo ao movimento hegeliano que ultrapassa a simples analogia. Também a música altamente organizada deve ser ouvida de forma multidimensional, ao mesmo tempo de frente para trás e de trás para frente. Seu princípio de organização do tempo exige-o: o tempo deve ser articulado apenas através da distinção entre o conhecido e o ainda náo conhecido, entre o que já estava ali e o novo; a própria progressão tem como condição uma consciência retroativa. É preciso conhecer uma frase inteira [einen ganzen Satz (lembrar que Satz também pode ser "movimento")] e estar atento, retrospectivamente, a cada instante anterior. As passagens individuais devem ser compreendidas como consequências daquilo que veio anteriormente, o sentido de uma repetição divergente deve ser compreendido, aquilo que reaparece não deve ser percebido como simples correspondência arquitetônica, mas como um devir necessário. Talvez ajude à compreensão dessa analogia, assim como do núcleo do pensamento de Hegel, o fato de a apreensão da totalidade como identidade em si mesma mediada pela não-identidade ser uma lei da forma artística transposta para a filosofia. A transposição é ela própria motivada filosoficamente (Adorno, Gs 5, 366-367).

Notemos o teor da declaraçáo de Adorno: a "identidade em si mesma mediada pela não-identidade", cujo modelo proveniente de uma "lei da forma artística" seria transposta para a filosofia pela filosofia, corresponderia à totalidade dinâmica do período médio de Beethoven. Na medida em que o esquema é permeado pela liberdade subjetiva, projeta-se uma nova totalidade que acolhe o não-idêntico em uma "síntese não violenta”, e dessa operação resulta posteriormente a forma. Exposição e desenvolvimento não

I4 Adorno, 1993, \$27: “O 'espírito’, mediação, é o todo como forma. A categoria que, nesse contexto, é idêntica entre filosofia e música, é trabalho [Arbeit]. O que é chamado trabalho do conceito em Hegel é trabalho temático na música”. 
são mais justapostos lado a lado pelo esquema, mas o próprio desenvolvimento surge como a consequência lógica da exposição, seu "devir necessário". Beethoven reconstrói o esquema formal "de baixo para cima", mediante a imersão dialética no particular, mediante o Arbeit temático. Por meio dessa lógica dedutiva e sistemática e em virtude da não-identidade da identidade, "a música atinge uma relação totalmente nova com o tempo" (GS I2, 68), não mais é indiferente a ele. Nesse sentido, a seção de reexposição [Reprise] no tipo intensivo - que Adorno compara à Erinnerung hegeliana - diverge tecnicamente daquela prevista no esquema da sonata clássica, de tal modo que, embora necessária para a "consciência retroativa", ela se coloca inicialmente como aporia, como momento crítico, diante do critério de irreversibilidade.

Em A forma da nova música, de 1966, Adorno esclarece que a reexposição era problemática para Beethoven, por ser um elemento formal "estranho ao tempo" (GS I6, 6I2), um elemento arquitetônico, espacialmente simétrico, que entra em conflito com a força de um material que "anseia livrar-se de toda repetição" (GS I6, 6I3). Assim, a reexposição sempre careceu de certa legitimidade na prática compositiva de Beethoven, uma prática "subjetivamente dinâmica" e "rigorosamente temática", nos termos de Adorno. Encontramos, grosso modo, a seguinte interpretação para o "problema da reexposição" no tipo intensivo: não se trata da negação abstrata do universo do culto e da dança que circunscreve a música pré-clássica; a seção de reexposição, que deveria ser o "resultado do desenvolvimento [Durchführung]", consiste assim tanto na superação quanto conservação — negação determinada — do referente mítico da repetição. ${ }^{\text {I5 }}$

Enfatizemos mais uma vez a mediação que caracteriza a categoria de Entwicklung: ela seria internamente dialética em seu confronto com o tempo empírico, não no sentido de constituir um "terceiro termo" que resultaria da relação entre termos opostos — particularidade/totalidade ou instante/sucessividade - mas no sentido de manifestar a própria mediação interna da particularidade que assume a totalidade da forma, a mediação da sucessividade que se experimenta como instante. Essa relação intensiva da parte com o todo, revelada no instante como processo de auto-reflexão musical, estabelece, segundo Paddison (1993, p. 235), o caráter cognitivo da música de Beethoven. Como veremos a seguir, a verdade enunciada transcenderia o âmbito da ideologia. Daí o estatuto singular de "filosofia da música" que Adorno atribui à análise imanente:

O estudo sobre Beethoven deve fornecer a filosofia da música [die Philosophie der Musik geben], ou seja, deve estabelecer de modo decisivo a relação da música com a lógica conceitual. Só entấo a confrontação com a Lógica de Hegel, e com ela, a interpretação de Beethoven, será não uma analogia, mas a própria coisa (Adorno, I993, \$26).

I5 Por outro lado, encontramos a interpretação do capítulo "Mediação" de Introdução à sociologia da música (1962), na qual a reexposição se apresentaria também como "tributo forçado à essência ideológica” da época de Beethoven — um autoritário e afirmativo "é assim” (GS I4, 4I2), ao qual cede o compositor. 
Que "a própria coisa" no trecho acima esteja cingida pela experiência da Revolução de 1789 , pelo acontecimento deflagrador de um "novo tempo" do mundo e da consciência histórica de progresso, fica evidente na convergência sugerida entre Beethoven e Hegel. Tal convergência com o ideal revolucionário aparece nos fragmentos: "assim como a revolução não criou uma nova forma social, mas ajudou a romper uma estrutura já formada, o mesmo ocorreu com Beethoven em relação às formas musicais" (Adorno, 1993, \$84). Também no capítulo "Mediação" da Introdução à sociologia da música identificava-se na obra de Beethoven o protótipo revolucionário de uma "música que escapou de sua tutelagem social e se revelou esteticamente autônoma" (GS I4, 4II). A articulaçáo entre autonomia e a suspensão da ordem profana e vazia do tempo, evocando o conceito benjaminiano de kairós, perpassa a constelação adorniana, descortinando com isso uma curiosa fraseologia teológica - de expressóes como kairós, "feliz epifania/ irrupção do instante" [glücklichen Einstand des Augenblicks], "confrontar o tempo" [die Zeit bewältigen] etc.

Em função da persistência da mesma constelação - observável em contextos e estágios distintos da produção adorniana (1937, 1949, I957, 1961, 1963, 1965) ${ }^{16}$ —, podemos deduzir que o tipo intensivo estaria na base de uma ideia específica de processualidade, de articulação entre todo e particular, que forneceria os atributos essenciais da construção musical do tempo para Adorno. Acreditamos que o arco histórico no qual se registram as ocorrências é suficientemente abrangente para sustentar nossa hipótese: a de que Adorno concebe um modelo peculiar de desenvolvimento ligado ao trabalho motívico-temático em Beethoven, que, por sua vez, estabelece a própria "essência dialética" [dialektisches Wesen] da música, determinando a especificidade imanente do meio musical [do Medium] como "arte da articulação", em seu ideal qualitativo de exteriorização do não-idêntico.

\section{Tipo extensivo ou épico}

A problemática do "preenchimento" do tempo distingue basicamente o tipo intensivo do tipo extensivo ou épico, o que nos reconduziria à categorização proposta por Lukács em $A$ teoria do romance. No entanto, o tipo extensivo é a figura dialética que supera o tipo intensivo (ao contrário de Lukács, para quem drama e épica não estabelecem relação dialética entre $\mathrm{si}^{\mathrm{i7}}$ ). O tipo extensivo corresponderia ao complexo de modalidades temporais que renuncia à confrontação dialética e ao domínio do tempo como no sinfônico, configurando, entretanto, essa renúncia. É importante enfatizar os dois momentos: trata-se aqui da renúncia do tempo musical - o conceito de tempo musical, em Adorno,

I6 A saber: Zweite Nachtmusik (1937); Filosofia da nova música (1949); Critérios da nova música (1957); Mahler (196I); Über die musikalische Verwendung des Radios (1963); Strawinsky - Ein dialektisches Bild (1965). As referências não se limitam evidentemente a esses textos, mas, considerando suas datas de publicação, bastam para assegurar nossa hipótese.

I7 "Drama, lírica e épica - em qualquer hierarquia que sejam pensados — não são tese, antítese e síntese de um processo dialético, mas cada qual é uma espécie de configuração do mundo de qualidade totalmente heterogênea das demais" (Lukács, 2000, p. I35). 
devendo ser compreendido aqui no sentido intensivo - mas não da renúncia de uma configuração [Gestaltung], ou seja, de uma organização formal dessa renúncia do tempo. A distinção entre revogação do tempo, de um lado, e forma que configura a revogação do tempo, de outro, parece-nos tão importante quanto a oposição entre negação determinada e negação abstrata, pois é a partir dela que Adorno avançaria a crítica da "espacialização" temporal em Wagner e Stravinsky: ambos os compositores "renunciariam" à construção temporal da música, mas de modo abstrato, sem configurar tal revogação, cujo efeito "espacializa" o tempo musical. O extensivo em Beethoven procede de outro modo: compóe-se de dispositivos que criticam a contração do sinfônico, formalizando no plano técnico o "processo de desintegração" [Zerfallprozess].

O tipo extensivo corresponde, portanto, a um princípio de organização formal, marcado pela relação "geométrica", em vez de dinâmica, com o tempo empírico. Em obras do período médio-tardio - os primeiros movimentos da sinfonia Pastoral, do Trio op. 97, da última Sonata para Violino, op. 96 - Adorno observa então o abandono da ideia de totalidade dinâmica, a "des-dinamização" [Ent-Dynamisierung] do tempo musical. O extensivo consiste na redução da seção central de desenvolvimento [Durchführung] e na substituição do caráter processual do trabalho motívico por episódios historicamente sedimentados, modelos expressivos convencionais, repetiçóes estáticas de motivos. Longe de ser regressivo, trata-se de um momento "soberano" de crítica imanente, ou ainda, como defende Adorno, de auto-crítica da forma. No extensivo, Beethoven abstém-se de subjugar esteticamente o tempo empírico a um momento dialético, manifestando certa indiferença em relação ao dinamismo do trabalho temático. Não se retira mais o significado musical do presente contraído no instante, mas sim de algo como "já passado". Esse significado extensivo, descrito como efeito "retrospectivo" de desenvolvimento, mostra que, na realidade, a ideia de desenvolvimento teria sido descartada por Beethoven. Essa seria a razão de seu caráter épico.

Nos fragmentos sobre o Trio op. 97 - Arquiduque, acompanhados do subtítulo Elementos de uma teoria do tipo extensivo (1993, \$222), Adorno verifica certa tendência ao caráter de "recitativo" da obra, como contrapartida à sua falta de progressão temática; uma simplicidade inexplicável na construção do consequente do tema principal; transições harmônicas abruptas em vez de modulaçóes (a modulação parece excessivamente "cerimoniosa" no extensivo). A seção central de desenvolvimento reduz-se a um mero "episódio", sem valor significativo - apenas 17 compassos. Também o problema da reexposição diverge daquele do intensivo e vale aqui uma análise detida. No Trio op. 97, a reexposiçáo torna-se "discreta", "reticente", emerge em diminuendo (em $p p$ ), por não ser mais a culminação de uma atividade anterior conflitante e dinâmica, como no tipo intensivo. Não há mais a contrapartida "tectônica" do esquema tradicional da sonata nem o clímax do intensivo. Por isso, a entrada tímida da reexposição constitui um momento sensível da forma extensiva, ainda que por outras razóes: em função do caráter contingencial dos eventos musicais, "simplesmente náo se sabe mais como voltar ao começo. A reexposição é um tour de force [...]”. Como sintoma do aspecto contingencial, "a tônica 
é introduzida um compasso antes do início da reexposição (compasso 190)" (Adorno, 1993, \$222), ou seja, o evento harmônico principal, a cadência resolvida, antecipa-se à demarcação que inicia a seção da reexposição. Tornando-se quase imperceptível, confirma não mais ser a culminação de eventos tensionados. A reexposição converte-se em repetição, mera "lembrança de algo", o que, para Adorno, remete ao épico. Na coda, a harmonização é trivial, tautológica, convenção abstrata do elemento expressivo.

Se não há mediação temática no tipo extensivo, nem por isso há desintegração da forma. Do contrário, de acordo com o esquema histórico adorniano, o extensivo estaria na vizinhança conceitual e mítica do Divertissement que dominava a música pré-clássica. Daí a importância do segundo momento da forma do extensivo: a configuração subjetiva da desintegração, cujo efeito em "retrospecto" inaugura, segundo Adorno, uma música da "pura presença" (e não da "transcendência" no intensivo). Em sua propensão épica, o extensivo transformaria paradoxalmente a própria passagem do tempo empírico em tema - e não, como no intensivo, em kairós, confrontação e suspensão. $\mathrm{O}$ épico em Beethoven insinua a construção, como Adorno definirá no Ensaio sobre Wagner, de uma "metafísica da pura presença". Assim, a permutabilidade dos eventos temporais mostraria que a organização musical não mais obedece ao ideal de construção progressiva de sentido: o que vem depois poderia ter vindo antes. O primado da irreversibilidade, que qualifica o conceito de Entwicklung em sua progressividade, seria entâo questionado por Beethoven antes mesmo do estilo tardio. Ocorre que tal configuração da renúncia, vale insistir, se dá como crítica imanente ao tipo intensivo. Assim, a própria repetição motívica ocorre aqui em registro específico. Adorno constata, por exemplo, no $\mathrm{I}^{\mathrm{o}}$ movimento da Pastoral, modelo do extensivo ou do épico, um "tipo curioso de repetição": "[...] que beira a expressão de felicidade (como em certos estados catatônicos?) Encontramos aqui um motivo de certos desenvolvimentos modernos, de Stravinsky" (Adorno, 1993, \$217).

O processo de desintegração no épico de Beethoven seria semelhante aos expedientes modernistas de repetição em Stravinsky, fortemente criticada em FNM. Adorno (1993, \$243) chega mesmo a afirmar que a Pastoral “é, acima de tudo, música estática”. No entanto, se essa descrição sugere imediatamente uma analogia com a repetição analisada na seçấo "catatonia" de FNM, Adorno procura distinguir esse "tipo curioso de repetição" da Pastoral daquela "catatônica" da Sagração, ponderando que, ao contrário de Stravinsky, a repetição em Beethoven não resulta de uma compulsão, de um "motorismo" que coloniza a rítmica, mas, pelo contrário, "de um relaxamento, de um deixar estar [Loslassen]" (Adorno, I993, \$244), viabilizada de maneira “soberana” pela subjetividade composicional.

As metáforas associadas ao extensivo, por vezes náo muito convincentes, parecem confirmar o desconcerto de Adorno quanto a esse princípio de configuração da forma extensiva - "muito difícil de determinar", "ainda obscuro para mim”, como o autor pondera no fragmento \$219. Adorno compara o épico em Beethoven ao "relaxamento" da forma após o domínio do tempo sinfônico no intensivo, como se a forma precisasse "respirar". Compara a "uma expiração, como se fosse impossível permanecer no 
topo paradoxal do sinfônico" intensivo $(\$ 22 \mathrm{I})$. E atribui ao tipo extensivo uma "auto-contemplação" da forma, na qual a música náo deseja mais transcender, deseja apenas "ficar aqui" (metafísica da presença), como se o tempo fosse liberado da relação de dominação subjetiva para ser apenas retratado ou "preenchido", deixando de constituir um desafio ao "tédio" [Langeweile]. Ao contrário da concentração no tipo intensivo, o objetivo composicional no tipo extensivo seria ainda um percurso e um devir, mas este se apresenta "como episódio, não mais como processo" (ibid., \$222); por isso, a seção da reexposição possui geralmente certa qualidade "irresponsável”. O momento épico corresponderia, afinal, à percepção de que o tempo é mais poderoso do que sua sincopação estética, sincopação esta que somente o tipo intensivo realizaria (ibid., \$223). De fato, "relaxamento", "ausência de pressa", "irresponsabilidade", "expiração", compóem uma terminologia vacilante, de pouca precisão técnica e de cuja descrição em termos analíticos Adorno parece recuar.

Apesar disso, interessa-nos constatar que as modalidades da relação da música com o tempo em geral se depreendem claramente a partir de dois conjuntos da obra de Beethoven. Se enfatizamos a constatação, é porque, a partir dela, tanto podemos questionar a acusação de que Adorno encontraria apenas na obra de Beethoven o modelo para a formalização da Entwicklung (a acusação bastante comum de certo "monismo" na apreciação de Beethoven ${ }^{18}$ ) quanto podemos questionar a hipótese de que a espacialização do tempo seria um processo totalmente moderno, que caracterizaria a obra de Stravinsky após o colapso do sistema tonal. Os fragmentos desmentem as duas hipóteses. Em primeiro lugar, o ideal de Entwicklung, embora atinja seu ápice no período médio de Beethoven, nasce com a "antifonia motívica" do classicismo; em segundo lugar, os primórdios do processo da espacialização do tempo musical estariam prefigurados na estaticidade do tipo extensivo, em obras no período médio-tardio de Beethoven (como o Trio Op. 97 e a Pastoral). Do mesmo modo, a categoria de sinfonia épica (em oposição à dramática), um dos pontos centrais da monografia sobre Mahler, pertenceria ao tipo extensivo. A sinonímia entre épico e extensivo como crítica da totalidade dramática indica uma possibilidade de apreciação progressista da própria renúncia do tempo musical. Para sermos mais claros: por um lado, o afastamento do ideal de Entwicklung em direção à "totalidade épica” em Wagner ou à "dissociação do tempo" em Stravinsky são considerados desvios da essência da música, retração da consciência. Por outro, quando o assunto é Mahler e Berg, o afastamento desse ideal em direção a processos formais de desintegração do material é tomado como progressista. Essa ambivalência judicativa levou Dahlhaus a afirmar que o conceito de tempo adorniano é politicamente "decisionista"

I8 Cf. Klein, 20II, p. 64: há "discrepância entre a pluralidade das descriçôes de fenômenos particulares e o monismo de sua escolha fundamental conceitual (da Entwicklung em Beethoven)". Ou ainda Schneider, I987, p. 80: "O sentença de Adorno sobre o tempo na música estabelece um paralelo com sua filosofia da história. Como presumivelmente só existe uma história, então só há uma forma de configuração temporal [Zeitgestaltung] e experiência temporal [Zeiterfahrung] na música". 
e esteticamente "subjetivista". ${ }^{19}$ Isso nos obriga a expor, por exemplo, de que modo o maneirismo e a desintegração épica em Mahler percorrem autenticamente a senda crítica aberta pelo tipo extensivo em Beethoven, enquanto a "espacialização" em Stravinsky diverge deste caminho, por se colocar como desvio da necessidade de configuração do tempo. Trata-se, com efeito, do problema central na interpretação da teoria dos tipos. ${ }^{20}$

Embora a relação com critério da escuta seja sem dúvida determinante ${ }^{21}$, parece-nos que a complexidade da teoria dos tipos, em consonância com a prerrogativa materialista da primazia do objeto, passa antes de tudo pela compleição da totalidade da forma na escrita composicional de Beethoven e pela sua relação crítica com o momento histórico de produção. Ou seja, a configuração compromete-se historicamente com a configuração da sonata, ao passo que os modos de audição que Adorno descreve em FNM referem-se a tipos ideias. Este seria, afinal, o substrato autêntico do modelo de "filosofia da música" que, segundo Adorno, poderia ser implementado.

Cabe ressaltar que o colapso do tipo intensivo resulta, no plano técnico, da auto-crítica promovida pelo tipo extensivo. No entanto, resultaria também da negação do elemento social, da função decorativa e arcaica de "preenchimento do tempo", vinculado ao lugar social da música. Em sua antítese à empiria, Beethoven sinalizaria, com a configuração do extensivo, o abandono da utopia de irreversibilidade e de contração temporal na música. As condiçóes sociais objetivas e os desdobramentos dos acontecimentos históricos posteriores (como o Congresso de Viena de I8I4) mostrariam o caráter ideológico de um modelo de temporalidade que institui a transcendência do kairós, a experiência no instante da reconciliação entre universal e particular. Vários comentadores afirmam, nesse sentido, que o tipo extensivo de Beethoven forneceria os parâmetros da interpretação adorniana sobre a "dissociação do tempo", modulada conforme o objeto de análise, seja na interpretação de Schubert, de Wagner a Debussy, de Schoenberg a Stravinsky. ${ }^{22}$ Contudo, a dialética em Beethoven não se estabilizaria na crítica ao momento ideológico de uma totalidade fechada. Se o tipo extensivo, enquanto configuração [Gestaltung], havia sido a crítica imanente do intensivo, o estilo tardio, em nova torção dialética, surgirá da própria configuração do extensivo - o estilo tardio consistiria entáo na terceira figura da dialética do tempo musical. ${ }^{23}$

I9 Dahlhaus, 1987, p. I4: "A filosofia da história adorniana - a höhere Kritik — pode ser desmembrada em, de um lado, 'decisionismo' político e, de outro, 'subjetivismo' estético”.

20 Urbanek (20IO, p. 213) também critica essa ambivalência no tratamento da dissociação temporal em Beethoven, Mahler e Stravinsky.

2I Boissière interpreta a distinção entre os tipos intensivo e extensivo a partir de um critério de escuta (2oII, p. 56). Na mesma linha, Tiedemann considera que a distinção corresponde aos tipos de audição que Adorno propóe em FNM, o expressivo-dinâmico e o rítmico-espacial; ver nota de Tiedemann ao fragmento 219 .

22 Klein (20II, pp. 64-65) enumera as interpretaçóes nas quais a crise do modelo da Entwicklung estaria no horizonte especulativo adorniano: "associação lírica em Schubert, dissociação mítica em Wagner, extensão épica em Mahller, progressão em Schoenberg, espacialização em Debussy, fragmentação cronométrica em Stravinsky".

23 Adorno, 1993, \$220: "A teoria do tipo extensivo deve ser entendida assim: como crítica do Beethoven clássico e como configuração, cuja crítica envolve o Beethoven tardio. Origem do Beethoven tardio." 


\section{Estilo tardio}

O estilo tardio advém de uma "relação complexa" entre os tipos intensivo e extensivo (cf. \$219 acima). Como consequência do extensivo, é marcado pela ausência de mediação e pelo processo de desintegraçáo [Zerfallprozess], mas também é marcado pelo esforço em se obter unidade, típico do intensivo, a partir dessa mesma fragmentação. A ideia de tentar articular a sinfonia integral (plenamente depurada no período médio) e a sinfonia épica (que domina, na periodização adorniana, não apenas as obras do extensivo mas, como vimos, "todo o período romântico" posterior a Beethoven, incluindo Schubert e Mahler), tal ideia compóe o enigma do estilo tardio. Na "colisão" dos tipos divergentes, o estilo tardio representa o último estágio de auto-crítica do conceito de tempo musical:

O contraste entre o tipo intensivo e extensivo é talvez a explicação para a famosa duplicidade das obras de Beethoven. Os primeiros movimentos da $5^{\mathrm{a}}$ e da $6^{\mathrm{a}}$ sinfonias estão entre os exemplos mais puros de cada tipo. O estilo tardio é a colisão entre esses dois tipos. Um pré-requisito para compreender o Beethoven tardio é portanto a consciência dessa divergência. Em outras palavras: o que Beethoven perdeu nas obras integrais, os primeiros movimentos da $3^{\mathrm{a}}, 5^{\mathrm{a}}, 9^{\mathrm{a}}$, Appassionata, a 7 ? Essa questáo conduz ao limiar do segredo de Beethoven. Ela pergunta o que o idealismo deixou para trás no avanço triunfal do progresso (Adorno, 1993, \$263).

O fragmento é enfático: para compreender o estilo tardio (sem apelar a elementos biográficos, seja a surdez ou a velhice, irrelevantes sob o aspecto evolutivo da técnica), é preciso ter consciência da coexistência dos tipos intensivo e extensivo, no período médio do compositor. Ao se colocar como crítica imanente do tipo extensivo, o estilo tardio não esconde certo acento nostálgico e arcaizante. As obras do estilo tardio revelariam a "dessensibilização" do material, uma tendência mais pronunciada à dissociação, as inconsistências, cesuras e falhas estruturais que, no entanto, apontam para a verdade histórica. Eliminando o superficial, vinculam-se a convençôes, mas estas aparecem libertadas de qualquer ornamentação, despojadas da "aparência" [Schein]: a convenção se apresenta sem estilização, sem aspirar à autenticidade. No conhecido ensaio de 1937 sobre estilo tardio de Beethoven, Adorno afirmava que a força da subjetividade tardia residia na paradoxal adesão a fórmulas convencionais que, apresentadas como tais, como puras convençôes, falam por si e se tornam paradoxalmente expressão sem aparência.

No estilo tardio, do ponto de vista técnico, excedem os motivos banais, arpejos "desajeitados" e melodias cuja falta de plasticidade causa espanto, em virtude do que Beethoven já havia obtido anteriormente. A melodia da sonata op. I06 Hammerklavier, por exemplo, "não contém pausas, contrastes rítmicos acentuados, sua base harmônica permanece idêntica durante toda apresentação do tema. A melodia perde imediaticidade" (Adorno, 1993, \$266). No plano vertical, constata-se o uso de harmonias modais, acompanhamentos primitivos e insistentes. Quanto à textura, a característica fundamental do estilo tardio consiste em certa tensão provocada pelo retorno da polifonia após a consolidação da monodia. Já o Finale da sonata op. IOI, "protótipo do estilo tardio" (ibid., \$265), marca o retorno da fuga no interior da sonata; aqui, o uso de procedi- 
mentos contrapontísticos provenientes do barroco — cânone e fuga — "colide" com o esquema monódico e homofônico da sonata clássica, de modo que a identidade do tema em fuga é então desfigurada ao sofrer eventuais mutaçóes pelo procedimento de variações. Tais variaçóes não se apresentam, contudo, como obrigatórias, pois a forma do estilo tardio incorpora a fuga como pura convenção, preservando ocasionalmente a identidade temática.

Por fim, ao analisar o Quarteto op. I32, Adorno oferece uma interpretação prodigiosa da fusão entre polifonia e homofonia no interior do trabalho temático no tipo intensivo, bem como de sua posterior dissociação e fragmentação no estilo tardio, mediante a dissolução da aparência:

O dito trabalho temático, que Beethoven estabeleceu [...], é via de regra uma segmentação e uma ruptura de algo unificado - uma melodia. Não é a genuína polifonia, mas a aparência desta polifonia dentro composiçâa harmônica-homofônica. Para o Beethoven tardio, isso parece supérfluo [...] é a grande rebeldia da música contra o ornamental (Adorno, 1993, \$269, grifo meu).

Ou seja, o trabalho temático, como aparência da polifonia dentro do esquema da sonata clássica, é simplesmente descartado no estilo tardio, porque a própria polifonia como tal, a polifonia "genuína" da fuga, retorna como convenção. O estilo tardio quebra, portanto, a fusão aparente da polifonia e da monodia subsumida no tipo intensivo em sua composição homofônica e expóe essa ruptura em fragmentos, polarizados em extremos. É nesse sentido que compreendemos a afirmação do conhecido ensaio de 1937 de que o estilo tardio "ainda é processo; mas não mais como desenvolvimento [Entwicklung], e sim como igniçâo [Zündung] entre os extremos, que, da espontaneidade, não tolera mais um meio seguro ou harmonia" (Adorno, Gs 17, I6).

Aquilo que, como aparência, apresentava-se de maneira ornamental e elaborada é agora exposto de maneira abrupta e direta, como pura convenção dissociada, e ela já não se integra à estrutura da obra. Adorno insiste no fato de que a característica principal do estilo tardio não seria o uso da convenção em si, mas a fricção que o retorno de convençóes, como elementos estereotipados da fuga, provoca ao se ajustarem no plano harmônico-homofônico, o que acaba enfraquecendo este último:

No Beethoven tardio, não é tanto a polifonia o que me parece tecnicamente decisivo; isso é mantido dentro dos limites e de modo algum forma o estilo inteiro, possuindo, em vez disso, um caráter episódico. É, realmente, a ruptura em extremos: entre polifonia e monodia. É uma dissociaçấo do meio. Em outras palavras: é a perda do vigor da harmonia" (Adorno, 1993, \$31I).

Daí a contradição na experiência com as obras do estilo tardio: de superfície simples, às vezes inexpressiva, distanciada, de um material não processado, elas são ao mesmo tempo grandiosamente enigmáticas. Por fim, convém notar que nem todas as obras tardias fazem parte do estilo tardio: para Adorno, o I ${ }^{\circ}$ movimento e o Scherzo da

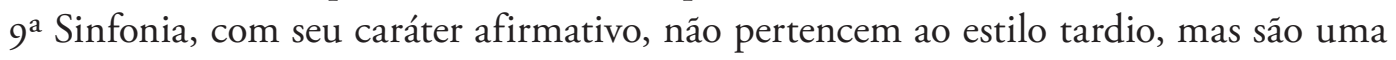


reconstrução do período médio clássico. Compor a $9^{\mathrm{a}}$ sinfonia provaria retroativamente que "o estilo tardio de Beethoven é essencialmente crítico. Que Beethoven ainda era 'capaz' de compor como antes — náo importa o quanto isso seja irrelevante para a compreensão do estilo tardio - mostra sua intenção crítica" (Adorno, 1993, \$223).

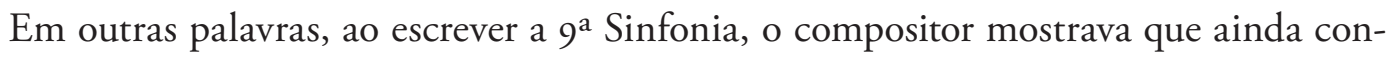
seguia compor obras de tipo intensivo. O "estranhamento" ocasionado pelas obras do estilo tardio revelaria sua intencionalidade crítica.

É com o estilo tardio que Beethoven teria realizado "a crítica da identidade da identidade com a não-identidade", ou seja, a crítica imanente tanto do tipo intensivo quanto do tipo extensivo a partir do percurso de sua própria obra. Na tendência à fragmentação, o estilo tardio cria, a partir de sua pura força construtiva, um senso de unidade de segunda ordem. Edward Said, em seu comentário sobre o estilo tardio em Beethoven (e Adorno), sublinha o impulso de negatividade incessante:

As obras tardias de Beethoven não se deixam apaziguar ou cooptar por uma síntese superior, não se conformam a nenhum esquema e não podem ser resolvidas ou conciliadas, uma vez que seu caráter não resolvido, sua fragmentaridade não sintetizada são constitutivos, sem nada de ornamental ou simbólico. As composiçôes tardias de Beethoven lidam com a "totalidade perdida", e é isso que as torna catastróficas (Said, 2012, pp. 32-33).

São catastróficas, mas, ao se expor como crítica da tonalidade na tonalidade, o estilo tardio fornece um modelo único de crítica da ideologia. É nesse sentido que podemos finalmente compreender a veemência da afirmação adorniana: "a música de Beethoven é a filosofia de Hegel: é, porém, mais verdadeira do que esta” (Adorno, 1993, \$29).

Nessa sentença surpreendente, Adorno refere-se não ao tipo intensivo, em sua construção da totalidade pelo particular, nem ao extensivo, mas ao estilo tardio, como modelo de crítica imanente, no meio musical, da categoria de totalidade, do absoluto hegeliano. Em sua fratura, em sua crítica da aparência da própria tonalidade, o estilo tardio denunciaria o caráter ideológico de reconciliação entre universal e particular, proveniente do modelo liberal clássico da sociedade burguesa no qual se inscreve. ${ }^{24}$ Com o estilo tardio, a exigência de totalidade tornou-se insuportável, restando no entanto uma reminiscência da síntese. Nas paradas abruptas, na justaposição inesperada de convençóes sem mediação subjetiva, sobressai a renúncia à síntese subjetiva, que pareceria falsa, ideológica: a Entwicklung se interrompe, os fragmentos não são reconciliados. No ensaio de 1959 sobre a Missa Solemnis, Adorno retoma a ideia: "A exigência pela verdade do último Beethoven rejeita a aparência ilusória da unidade do subjetivo e do objetivo [...]. Resulta uma polarização. A unidade transcende para o fragmentário" (GS I7, I59).

Tornando-se "mais verdadeiro do que a filosofia de Hegel", o estilo tardio revelaria

24 Adorno, GS I7, 284: "Não é acidental que a tonalidade foi a linguagem musical da era burguesa. A harmonia do universal e do particular correspondia ao modelo liberal clássico da sociedade [...]. Esse modelo nunca foi adequado à realidade, mas foi em larga medida ideologia”. 
então ser a negação determinada, no ato de renúncia dessa aparência, a que primeiramente levou Beethoven ao tipo extensivo: converte-se finalmente na crítica da identidade da identidade com a não-identidade. Lembremos que, para Hegel, as proposiçóes "o todo é o verdadeiro" e "o verdadeiro é o todo" não são equivalentes; "o todo é o verdadeiro", somente porque o todo está subordinado ao conceito de verdade, a razáo existente, de modo que o absoluto corresponderia à "identidade da identidade com a não-identidade" (Scheibele, I969, p. 62). Para Adorno, todavia, a música de Beethoven supera a filosofia de Hegel, pois abre máo de um conceito positivo de verdade, deixando para trás a síntese conceitual pela força estética de uma unidade dispensada de juízos: o estilo tardio de Beethoven evidenciaria, afinal, que o todo é o náo verdadeiro. Dito por extenso: a própria dialética negativa.

\section{Referências bibliográficas}

Adorno, T. W. (1986/2003). Gesammelte Schriften in 20 Bänden (GS) (Obras reunidas em 20 volumes). Frankfurt am Main: Suhrkamp Verlag, I986/Berlin: Directmedia-Surkhamp, 2003 [Digitale Bibliothek, CD-ROM]. (no texto, as referências aos volumes da coleção das "Obras reunidas" seguem o formato "GS [vv], [PP]", onde Vv corresponde ao volume da coleção e pp a paginação dentro do volume).

(2004). Beethoven - Philosophie der Musik: Fragmente und Texte. R. Tiedemann (Org.). Frankfurt am Main: Suhrkamp.

Arantes, P. E. (200o). Hegel: a ordem do tempo. São Paulo: Hucitec/Polis.

Boissière, A. (20II). La pensée musicale de Theodor W. Adorno: l'épique et le temps. Paris: Beauchesne.

Churgin, B. (1998). "Beethoven and the New Development-Theme in Sonata-Form Movements." In: The Journal of Musicology, I6(3).

Dahlhaus, C. (1987). "Das Problem der 'höheren Kritik': Adornos Polemik gegen Strawinsky.” In: Neue Zeitschrift fur Musik, (I48/5).

(1989). "Emancipation of the dissonance." In: Schoenberg and the New Music: Essays by Carl Dahlhaus. Cambridge: Cambridge University Press.

Hegel, G. W. F. (2002). Fenomenologia do espirito. Trad. P. Meneses. Petrópolis: Editora Vozes.

JaY, M. (1995). As idéias de Adorno. Trad. A. U. Sobral. São Paulo: Cultrix.

KLEIN, R. (2004). "Überschreitungen, immanente und transzendente Kritik. Die schwierige Gegenwart von Adornos Musikphilosophie.” In: W. Ette (Org.), Adorno im Widerstreit. Zur Präsenz seines Denkens. München: Alber.

(20II). "Die Frage nach der Musikalischen Zeit." In: Adorno-Handbuch: Leben - Werk - Wirkung. Stuttgart: Metzler, pp. 59-74.

LukÁcs, G. (2000). A teoria do romance. Trad. J. M. Mariani de Macedo. São Paulo: Editora 34.

Paddison, M. (1993). Adorno's aesthetics of music. New York: Cambridge University Press. 
SAID, E. W. (20I2). Estilo tardio. Trad. S. Titan Jr. São Paulo: Companhia das Letras.

Scheible, H. (1989). Theodor W. Adorno: mit Selbstzeugnissen und Bilddokumenten. Reinbek bei Hamburg: Rowohlt.

Schneider, R. (1987). "Strawinsky und Adorno.” In: B. Sonntag (Org.), Adorno in seinen musikalischen Schriften: Beiträge zum Symposion "Philosophische Äusserungen über Musik, Adorno in Seinen Musikalischen Schriften". Rogensburg: G. Bosse.

Schoenberg, A. (2010). Style and Idea: Selected Writings. L. Stein (Org.). Trad. L. Black. Berkeley: University of California Press.

Urbanek, N. (2010). Auf der Suche nach einer zeitgemäßen Musikästhetik: Adornos "Philosophie der Musik" und die Beethoven-Fragmente. Bielefeld: transcript Verlag.

Waizbort, L. (1992). Aufklärung musical. Consideração sobre a sociologia da arte de Th. W. Adorno na "Philosophie der neuen Musik"(Dissertação de mestrado [versão eletrônica]). usp, São Paulo. 